\title{
Photocatalytic Degradation of Reactive Yellow in Batch and Continuous Photoreactor Using Titanium Dioxide
}

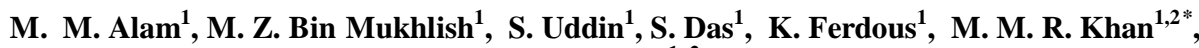 \\ M. A. Islam ${ }^{1,2}$ \\ ${ }^{1}$ Department of Chemical Engineering and Polymer Science, Shahjalal University of Science and \\ Technology, Sylhet 3114, Bangladesh \\ ${ }^{2}$ Faculty of Chemical and Natural Resources, Universiti Malaysia Pahang, 26300 Gambang, \\ Kuantan, Pahang, Malaysia
}

Received 26 September 2011, accepted in final revised form 29 May 2012

\begin{abstract}
Titanium dioxide $\left(\mathrm{TiO}_{2}\right)$ has been used as photo-catalyst for the degradation of reactive yellow (RY) in batch and continuous mode under UV irradiation. Titanium dioxide $\left(\mathrm{TiO}_{2}\right)$ was immobilized onto the ceramic plate using cement as binder. The effects of various parameters such as initial dye concentration, solution layer thickness, presence of catalyst, residence time, and catalyst loading on degradation have been investigated. The results showed that without catalyst no degradation was achieved. The maximum sorption capacity of $\mathrm{TiO}_{2}$ was found to be $0.01447 \mathrm{~kg} / \mathrm{kg}$. The degradation of RY followed pseudo-first order kinetics with rate constant $k=0.001 \mathrm{~min}^{-1}$. A decrease in degradation of RY was observed with an increase in initial concentration and solution layer thickness. A comparison of photocatalytic performance between batch and continuous mode was performed and the batch mode provided better degradation performance. About $60 \%$ degradation of dye was achieved at 360 min for 200 ppm RY solution in batch mode.
\end{abstract}

Keywords: Photocatalysis; Immobilized $\mathrm{TiO}_{2}$; UV light; Reactive yellow.

(C) 2012 JSR Publications. ISSN: 2070-0237 (Print); 2070-0245 (Online). All rights reserved. doi: http://dx.doi.org/10.3329/jsr.v4i3.8654 J. Sci. Res. 4 (3), 665-674 (2012)

\section{Introduction}

Dyes are one of the largest pollutants released in wastewater from textiles and other industrial processes. Because of potential toxicity of the dyes and their visibility in surface water, removal and degradation of reactive dyes have been a matter of considerable interest. Due to the synthetic nature of reactive dyes, biological treatment of wastewater alone is not usually effective for the removal of these chemical species. To meet increasingly stringent regulations, additional processes like coagulation, membrane separation or adsorption for the removal of these contaminants have been applied [1-3]. However, these processes simply transfer pollutants from aqueous to another phase, thus

*Corresponding author: mrkhancep@yahoo.com; mrkhan@ump.edu.my 
causing secondary pollution problem $[4,5]$. Photocatalytic oxidation is cost effective and capable of degrading any complex organic chemicals when compared to other purification techniques [6]. Usually, semiconductor particles with suitable band gap and flat band potentials/energy levels are used as photocatalysts. The semiconductors such as $\mathrm{TiO}_{2}$, $\mathrm{ZnO}, \mathrm{Fe}_{2} \mathrm{O}_{3}, \mathrm{CdS}, \mathrm{ZnS}$, and $\mathrm{ZrO}_{2}$ are employed. Heterogeneous photocatalysis is a process in which the irradiation of an oxide semiconductor produces photoexcited electrons $\left(\mathrm{e}^{-}\right)$ and positively charged holes $\left(\mathrm{h}^{+}\right)$. The photoexcitation of semiconductor particles, by means of light with a higher energy than the electronic band gap energy of the semiconductor, generates excess electron in the conduction band $\left(\mathrm{e}^{-}\right)$and an electron vacancy in the valence band. The excitation of $\mathrm{TiO}_{2}$ generates highly reactive electronhole pairs that in turn produce highly potent radicals (such as $\cdot \mathrm{OH}$ and $\mathrm{O}_{2}{ }^{-}$) to oxidize organic and inorganic pollutants [7]. Among the semiconductors, $\mathrm{TiO}_{2}$ is the most widely used photocatalyst, mainly because of its photo stability, non-toxicity, low cost and water insolubility under most environmental conditions [8]. In recent years, $\mathrm{TiO}_{2}$ photocatalysis has been successfully applied to remove organic and inorganic pollutants [9], to inactivate microorganisms [10], and to control disinfection by-product formation [11]. Although $\mathrm{TiO}_{2}$ photocatalysis was found to be effective for the destruction of a wide variety of environmental contaminants present in water and wastewater, this technology has not yet been successfully commercialized because of the costs and problems connected to the separation of $\mathrm{TiO}_{2}$ particles from the suspension after treatment.

In order to solve this problem, supported photocatalysts have been developed [12-14]. In this study, Reactive Yellow (RY) was chosen as model dye to test a novel photocatalytic reactor. The reactor containing $\mathrm{TiO}_{2}$ coated ceramic plate was operated in batch and continuous mode under UV irradiation at various conditions (with/without catalyst, different initial concentration and solution layer thickness). The performance of the reactor in batch and continuous mode were also compared.

\section{Experimental}

\subsection{Materials}

RY was supplied by a local textile industry and used as received. The catalyst $\mathrm{TiO}_{2}$ nanopowder primarily in the anatase form (70:30 anatase to rutile) was purchased from Merck, Germany. Water used in our experiments was triple distilled and produced in our laboratory.

\subsection{Preparation of photocatalytic plate}

$\mathrm{TiO}_{2}$ was mixed with cement at different ratios and the paste was made from the mixture with water. A thin layer of coating of the paste was made onto ceramic plate. There after it was kept in wet condition for a day and then dried at room temperature. 


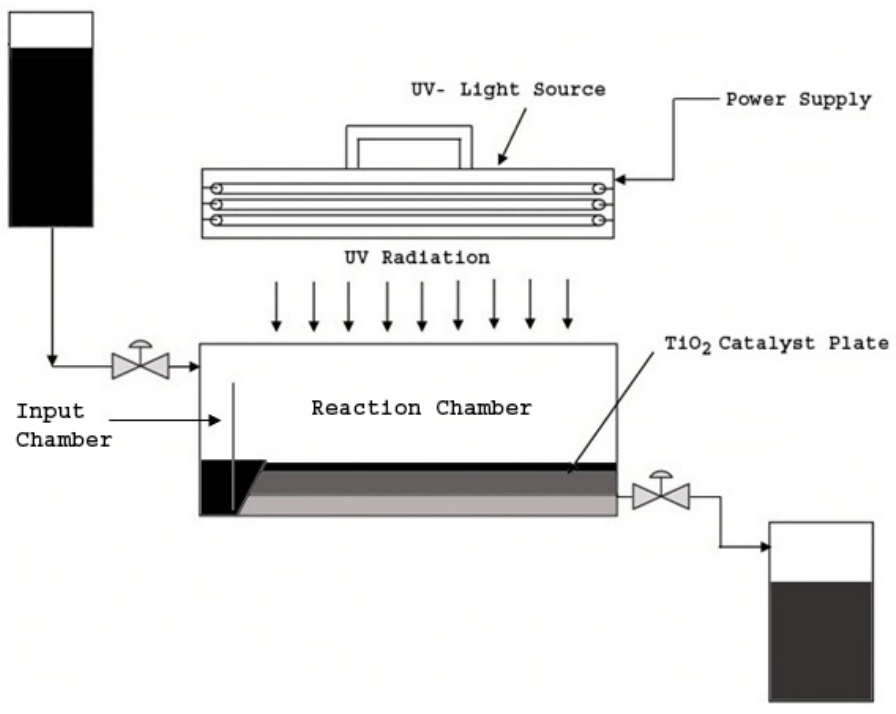

Fig. 1. Schematic diagram of the Photo-catalytic reactor.

After hardening the plate was subjected to heat treatment at $200^{\circ} \mathrm{C}$ for $2 \mathrm{~h}$ in a muffle furnace and the temperature was increased up to $450^{\circ} \mathrm{C}$ for another $2 \mathrm{~h}$. After heat treatment the plate was fully prepared for using in the photocatalytic reactor.

\subsection{Operation of the reactor}

The photocatalytic degradation of RY was evaluated in an aqueous solution under illumination of UV light (UV lamp, 100 watt) in a photoreactor system. The schematic diagram of the photoreactor is shown in Fig. 1. The reactor consists of a rectangular type box made by ceramic plates. The photocatalytic plate was placed on the floor of the box. The dimension of the reactor and photocatalytic plate were $40.5 \mathrm{~cm} \times 8.5 \mathrm{~cm} \times 10 \mathrm{~cm}$ and $34.5 \mathrm{~cm} \times 8.5 \mathrm{~cm}$, respectively. The UV lamp was placed on the top of the reactor at $10 \mathrm{~cm}$ apart from the catalyst plate. For continuous operation, residence time was adjusted by tuning the input and output valves. For batch experiments, the input and output valves were closed. The degradation process of RY was assessed by sampling $2 \mathrm{~mL}$ solution at appropriate time intervals. The concentration of RY was determined using UV spectrophotometer (UV-1650, SHIMADZU, Japan) by monitoring the absorbance.

\section{Result and Discussion}

\subsection{Adsorption isotherm for $\mathrm{RY}-\mathrm{TiO}_{2}$ system}

In order to find out the maximum adsorption capacity of $\mathrm{TiO}_{2}$, the experimental data of equilibrium RY adsorption on $\mathrm{TiO}_{2}$ were fitted to the Langmuir isotherm model. The 
Langmuir isotherm model assumes uniform energies of adsorption onto the surface of adsorbent and is represented by the following equation [15]:

$$
\frac{1}{q_{\theta}}=\frac{1}{K q_{x} C_{\ominus}}+\frac{1}{q_{\theta}}
$$

where, $q_{e}$ is the equilibrium adsorption capacity of the adsorbent ( $\mathrm{kg}$ dye $/ \mathrm{kg} \mathrm{TiO}$ ), $q_{\infty}$ is the maximum adsorption capacity ( $\mathrm{kg}$ dye $/ \mathrm{kg} \mathrm{TiO}_{2}$ ), $C_{e}$ is the equilibrium dye concentration in the solution ( $\mathrm{kg}$ dye/ $\mathrm{m}^{3}$ solution), and $K$ is the adsorption equilibrium constant. The plot of $1 / q_{e}$ versus $1 / C_{e}$ was found to be linear as represented in Fig. 2 . The Langmuir isotherm model parameters $\left(q_{\infty}\right.$ and $\left.K\right)$ were calculated from the slope and intercept of the plot and were estimated to be $q_{\infty}=0.01447 \mathrm{~kg} / \mathrm{kg}$ and $K=1.299 \mathrm{~m}^{3} / \mathrm{kg}$. The adsorption is well described by the Langmuir isotherm model as the equilibrium data fit to the isotherms with correlation coefficient $\left(r^{2}\right)$ of 0.950 .

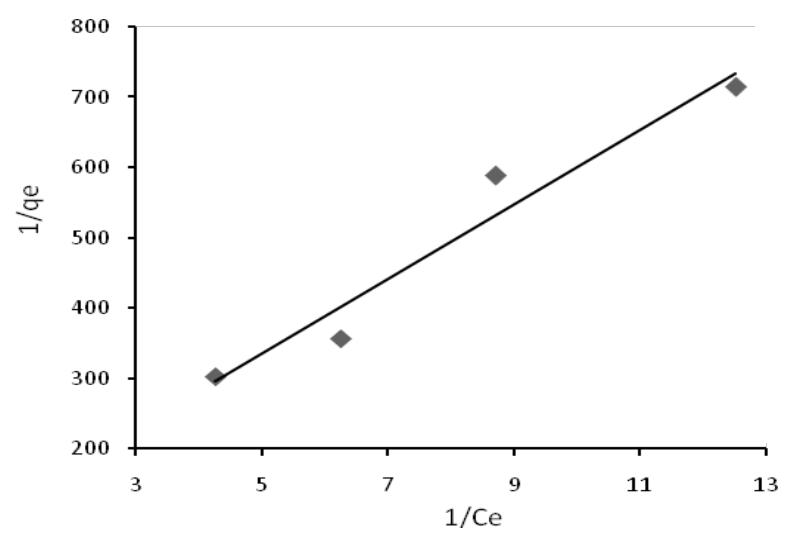

Fig. 2. Langmuir isotherm “Eq. (1)” plot for $\mathrm{RY}$ adsorption onto $\mathrm{TiO}_{2}$ plate. (Adsorbent dose $=50$ $\mathrm{kg} / \mathrm{m}^{3}$; Temperature $=26 \pm 2^{\circ} \mathrm{C}$, Initial RY concentration, $C_{0}=150,200,300,400 \mathrm{ppm}$ ).

\subsection{Photocatalytic activity of $\mathrm{TiO}_{2}$-cement plate in batch mode}

The potentiality of RY degradation is studied in batch mode at various operating parameters such as initial solution concentration and solution layer depth under irradiation with UV light.

\subsubsection{Effect of initial dye solution concentration}

The effects of different initial RY solution concentration ranged from 200-500 ppm on degradation of dye were studied in a batch type photo-catalytic reactor system in presence and in absence of catalyst. The catalyst dose was $5 \mathrm{~g} \mathrm{TiO}_{2} / 5 \mathrm{~g}$ cement (wt/wt) in an area of $0.029 \mathrm{~m}^{2}$ ceramic plate while the solution layer thickness was maintained at $3.7 \mathrm{~mm}$. The 
remaining solution concentrations after degradation of RY were plotted as a function of time in Fig. 3. It is evident from Fig. 3 that the concentration of RY remaining in the solution decreases with time while no degradation is observed in absence of catalyst. The initial concentration of RY influenced the UV light absorption on $\mathrm{TiO}_{2}$ catalyst. As the RY concentration increased, some of the UV light photons were absorbed by the substantial amount of dye molecules. The quantity of effective photons which was absorbed by the surface of catalyst was reduced. The quantity of excited $\mathrm{TiO}_{2}$ electrons produced by the effective photons decreased, making the generating holes lessened. As a result lower removal was achieved at higher concentration.

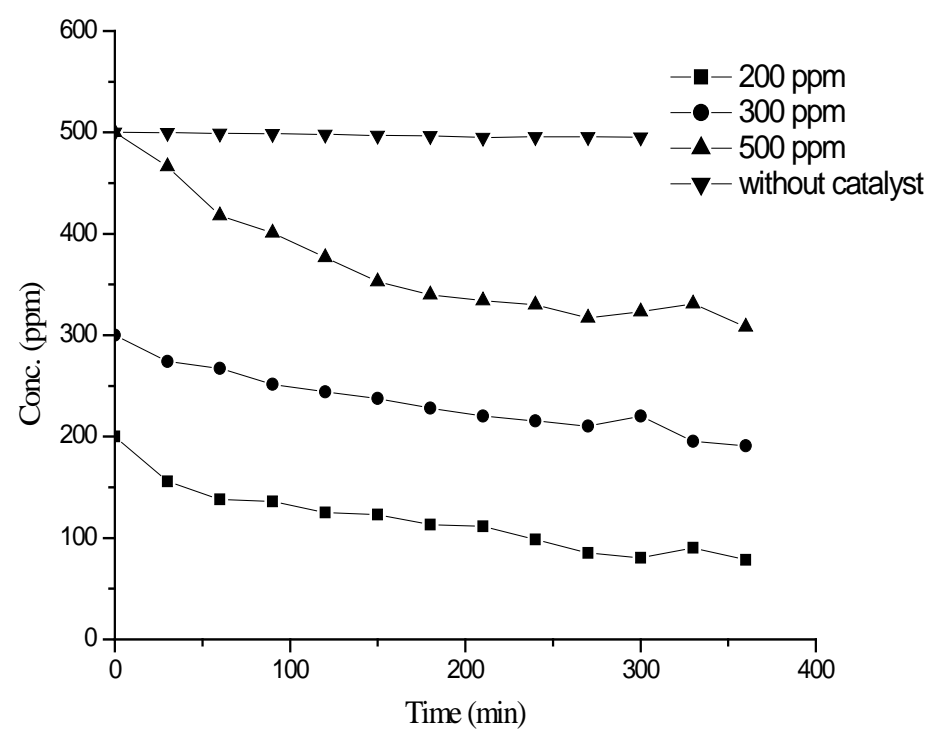

Fig. 3. Effect of different initial RY concentation on photodegradation. $\left(C_{0}=200,300,500\right.$ ppm; Catalyst dose $=5 \mathrm{~g} \mathrm{TiO}_{2} / 5 \mathrm{~g}$ cement; Irradiation time $=360 \mathrm{~min} ; \mathrm{T}=40^{\circ} \mathrm{C}$; Solution layer thickness $=3.7 \mathrm{~mm}$ )

\subsubsection{Effect of solution layer thickness}

Fig. 4 showed the effect of solution depth on the degradation of RY. The solution layer thickness was maintained at 2.77, 3.7 and $5.55 \mathrm{~mm}$ using 75, 100 and $150 \mathrm{~mL}$ solution respectively. As shown in Fig. 4, higher degradation of dye on the $\mathrm{TiO}_{2}$ surface was achieved at lower solution depth. The solution concentration droped from $300 \mathrm{ppm}$ to 175.3, 195.7 and $213.7 \mathrm{ppm}$ for the layer thickness of 2.77, 3.7 and $5.55 \mathrm{~mm}$, respectively. The more UV-light penetration capacity at lower solution thickness caused higher reduction in dye concentration. 


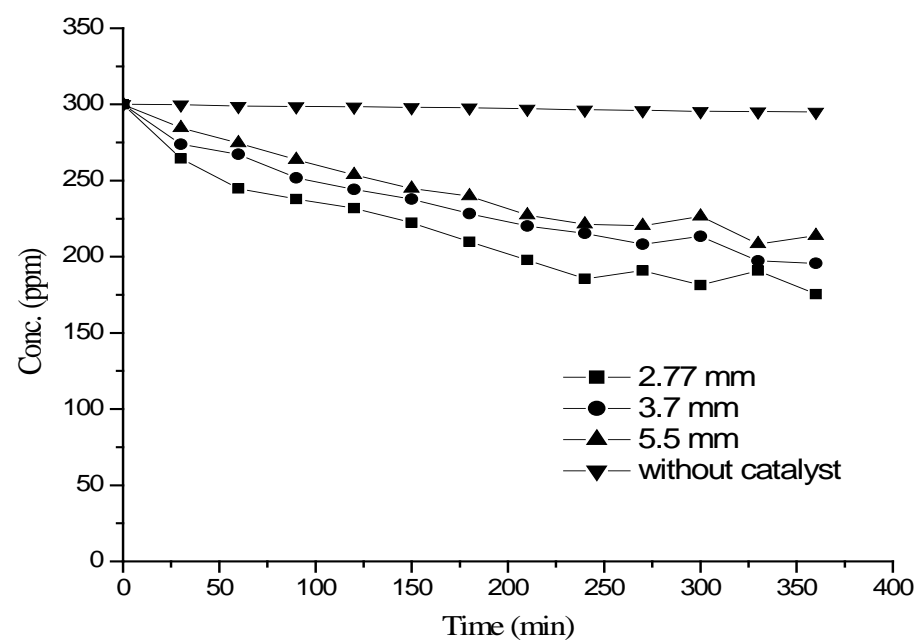

Fig. 4. Effect of solution depth on photodegradation. $\left(C_{0}=300\right.$; Catalyst dose $=5 \mathrm{~g} \mathrm{TiO}_{2} / 5 \mathrm{~g}$ cement; Operation time $=360 \mathrm{~min} ; T=40^{\circ} \mathrm{C}$; Solution layer thickness $=2.77$, 3.7, $5.5 \mathrm{~mm}$ )

\subsubsection{Pseudo-first order kinetics for photo-catalytic degradation of $R Y$}

The experimental data of photocatalytic degradation of RY was fitted to the Pseudo-first order kinetic model represented by the following equation:

$$
\ln \left(C_{0} / C\right)=k t
$$

A plot of $\ln \left(C_{o} / C\right)$ versus Time, $t$ for the photocatalytic degradation of RY at different initial concentration $\left(C_{o}\right)$ was found to be linear as shown in Fig. 5. The reaction rate constant $k$ was calculated from the slope of the straight line as $0.001 \mathrm{~min}^{-1}$.

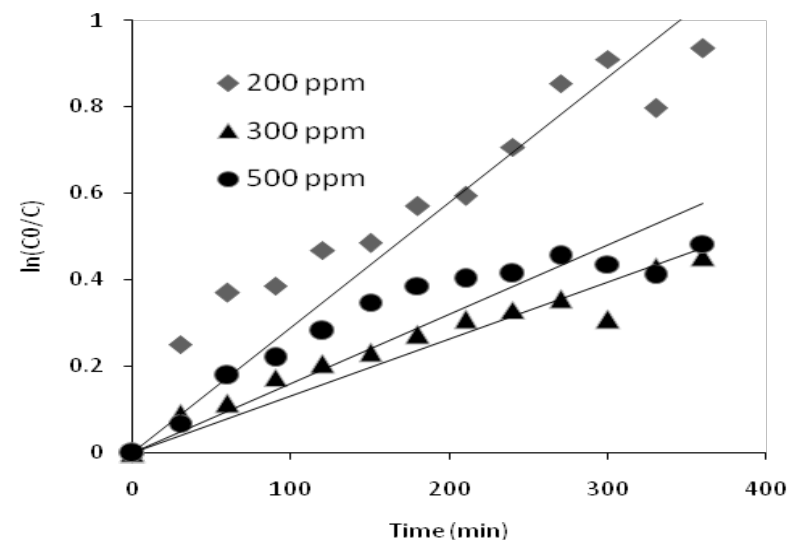

Fig. 5. $\ln \left(C_{o} / C\right)$ versus time plot for RY degradation. (initial concentration, $C_{0}=200$, 300, 500 ppm; Catalyst dose $=5 \mathrm{~g} \mathrm{TiO}_{2} / 5 \mathrm{~g}$ cement; Operation time $=360 \mathrm{~min} ; T=40^{\circ} \mathrm{C}$; Volume of solution $=$ $100 \mathrm{ml}$; solution layer thickness $=3.7 \mathrm{~mm}$ ). 


\subsection{Photocatalytic activity of $\mathrm{TiO}_{2}$ in continuous mode}

Numerous experiments were conducted at different initial concentration and residence time to investigate the potentiality of RY degradation under irradiation with 100 watt UVlamp in continuous photocatalytic reactor.

\subsubsection{Effect of residence time}

Fig. 6 demonstrated the results obtained from photocatalytic degradation of RY at various (50, 75 and $100 \mathrm{~min}$ ) solution residence times and constant initial concentration (200 ppm) under UV irradiation. The degradation efficiency of RY was found to increase with an increase in the residence time (Fig. 6). The remaining solution concentration increased from 95.8 to $156.5 \mathrm{ppm}$ as the residence time decreased from 100 to $50 \mathrm{~min}$. At higher residence time the dye molecules would get more time for degradation which could explain why higher removal was attained at higher residence time

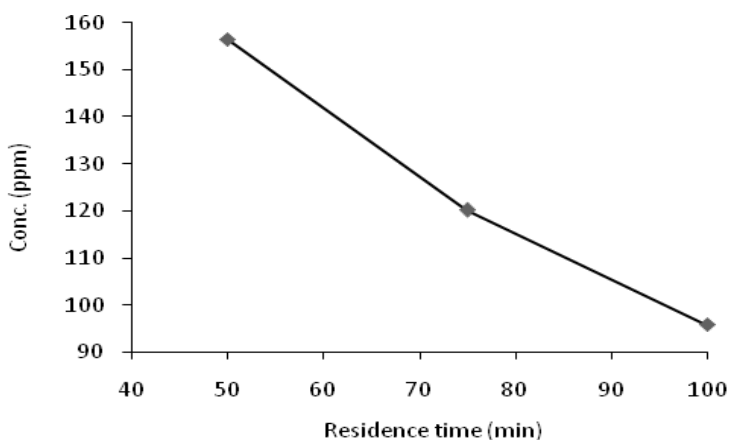

Fig. 6. Effect of residence time on photodegradation of RY at constant initial concentration in continuous mode. $\left(\mathrm{C}_{\mathrm{o}}=200 \mathrm{ppm}\right.$; Catalyst dose $=5 \mathrm{~g} \mathrm{TiO} / 2$ g cement; Operation time $=360 \mathrm{~min}$; $T=40^{\circ} \mathrm{C}$; Residence time $=50,75,100 \mathrm{~min}$; Flow rate $=1 \mathrm{mLO} / \mathrm{min}$.)

\subsubsection{Effect of initial concentration}

The effect of initial RY concentration on the degradation efficiency was studied by varying the concentration in the range of 200-300 ppm and keeping the flow rate as well as the solution layer thickness constant in a continuous type reactor and the obtained results are represented in Fig. 7. Without catalyst no degradation was found under UV illumination. For $\mathrm{TiO}_{2}$ catalyzed system, the RY solution concentration was found to be depleted with irradiation time. It could be found from Fig. 7 that RY concentrations decreased to 92.8 and 210.12 ppm from 200 and 300 ppm, respectively. The active surface on the catalyst available for reaction is very crucial for the degradation to take place, but as the dye concentration is increased and the catalyst amount is kept constant, results in fewer active sites for the reaction. With increased dye molecules the solution became more intense colored and the path length of photons entering the solution decreased thereby 
only fewer photons reached the catalyst surface. At still higher concentration of the dye, the path length was further reduced and the photodegradation was found to be decreased $[16,17]$.

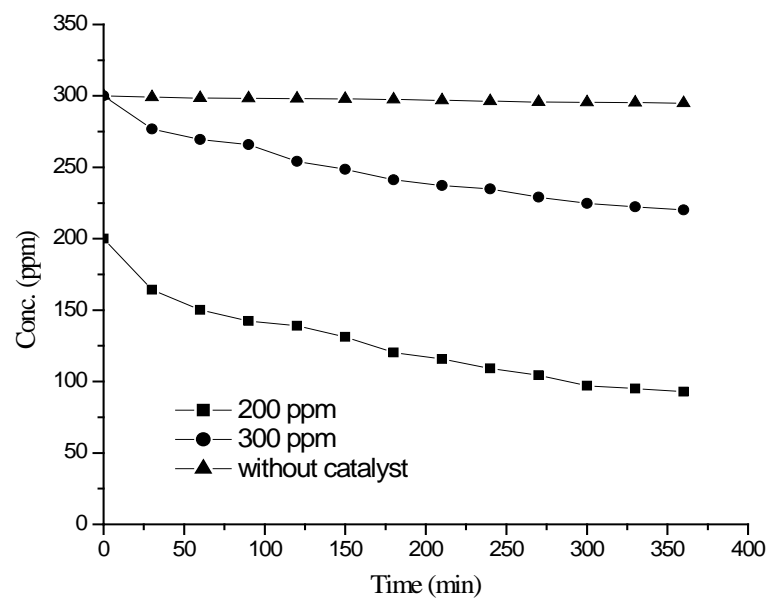

Fig. 7. Effect of initial solution concentration on photodegradation of RY at constant layer thickness in continuous mode. $\left(\mathrm{C}_{\mathrm{o}}=200,300 \mathrm{ppm}\right.$; Catalyst dose $=5 \mathrm{~g} \mathrm{TiO} / 2 \mathrm{~g}$ cement; Operation time $=$ $360 \mathrm{~min} ; T=40^{\circ} \mathrm{C}$; Solution layer thickness $=3.7 \mathrm{~mm}$; Flow rate $=1 \mathrm{~mL} / \mathrm{min}$.)

\subsection{Comparison of photocatalytic degradation between batch and continuous mode}

Fig. 8 shows the comparison of photo catalytic degradation performance between batch and continuous mode. From the figure it is apparent that the continuous mode shows lower RY degradation performance than batch mode at constant solution concentration and solution layer depth.

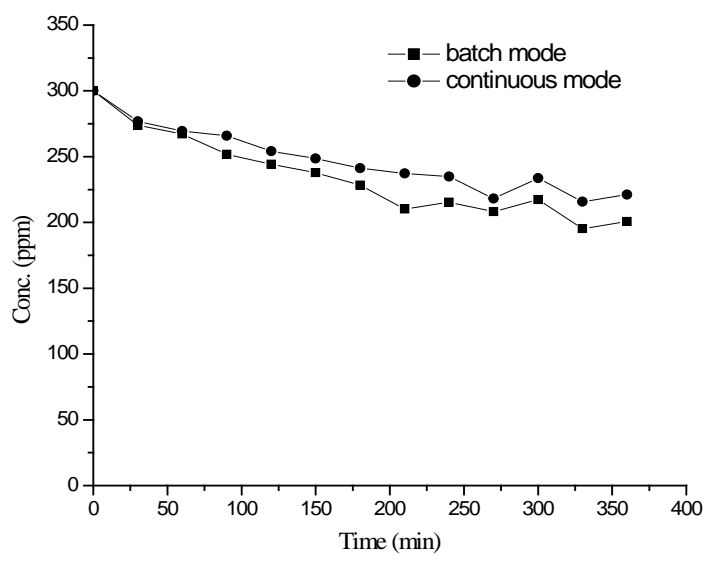

Fig. 8. Comparison of photocatalytic degradation of RY between continuous and batch mode at constant initial solution concentration and solution depth. $\left(C_{\mathrm{o}}=300 \mathrm{ppm}\right.$; Catalyst dose $=5 \mathrm{~g} \mathrm{\textrm {TiO } _ { 2 }}$ $15 \mathrm{~g}$ cement; Irradiation time $=360 \mathrm{~min} ; T=40^{\circ} \mathrm{C}$; Solution layer thickness $=3.7 \mathrm{~mm}$.) 


\subsection{Effect of catalyst dose in photo-catalytic plate}

The performance of photocatalytic plate depends on the catalyst dose. The photocatalytic plates loaded with different doses of catalyst e.g., $\mathrm{TiO}_{2}$ to cement ratio 1:1 and 1:2 g/g, were used to evaluate the degradation performance of RY and the results were represented in Fig. 9. It is clear from the figure that the catalytic decomposition performance enhances as the $\mathrm{TiO}_{2}$ fraction increases in the catalyst film. The more active sites of catalyst at higher dose provided better photocatalytic degradation under UV light. Further increase of $\mathrm{TiO}_{2}$ dose in the plate could not be possible. In case of higher dose of $\mathrm{TiO}_{2},\left(\mathrm{TiO}_{2}\right.$ : cement $=2: 1$ ) the catalyst particles were not hold onto the surface.

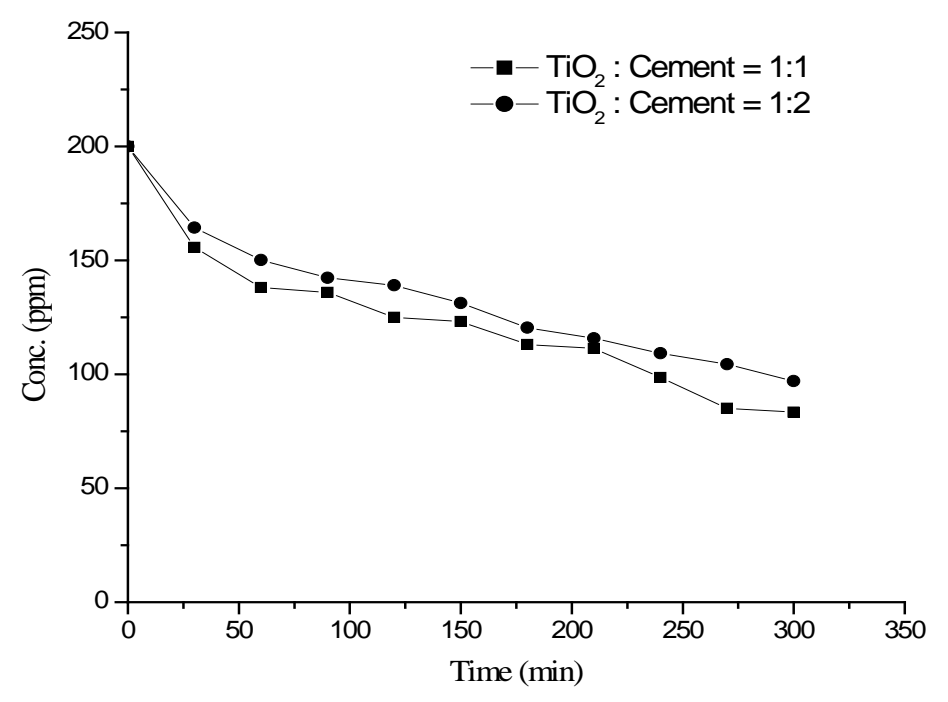

Fig. 9 Effect of catalyst dosage in photo-catalytic plate on RY degradation. $\left(C_{0}=200 \mathrm{ppm}\right.$; Catalyst dose $=5 \mathrm{~g} \mathrm{TiO}_{2} / 5 \mathrm{~g}_{\text {cement, }} 5 \mathrm{~g} \mathrm{TiO}_{2} / 10 \mathrm{~g}$ cement ; Operation time $=300 \mathrm{~min} ; T=40^{\circ} \mathrm{C}$; Solution layer thickness $=3.7 \mathrm{~mm}$ )

\section{Conclusion}

Photocatalytic degradation using $\mathrm{TiO}_{2}$ was successfully applied for textile dye (Reactive Yellow). Photocatalytic reactor with an immobilized $\mathrm{TiO}_{2}$ nanofilm was developed for continuous and batch process. The degradation of RY was strongly influenced by initial dye concentration, solution layer thickness and catalyst dose. No decomposition of RY was observed without catalyst. The monolayer sorption capacity of RY onto $\mathrm{TiO}_{2}$ was found to be $0.01447 \mathrm{~kg} / \mathrm{kg}$. The rate constant of RY degradation was $0.001 \mathrm{~min}^{-1}$. A comparison of photocatalytic performance between batch and continuous mode was performed and the batch mode provided better degradation performance. About $60 \%$ degradation of dye was achieved at 360 min for 200 ppm RY solution in batch mode. 


\section{References}

1. P. S. Kumar, S. Ramalingam, C. Senthamarai, M. Niranjanaa, P. Vijayalakshmi, and S. Sivanesan, Desalination 252, 149 (2010).

2. M. S. I. Mozumder and M. A. Islam, J. Sci. Res. 2, 567 (2010). http://dx.doi.org/10.3329/jsr.v2i3.4302

3. M. A. M. Arami, N. M. Mahmoodi, and A. Akbari, Desalination 267, 1107 (2010).

4. B. Ohtani, Y. Ogawa, and S. I. Nishimoto, J. Phys. Chem. B 101 (19), 3746 (1997).

5. X. Chen and S. S. Mao, Chem. Reviews 107, 2891 (2007). http://dx.doi.org/10.1021/cr0500535

6. G. M. Madhu, M. A. L. A. Raj, and K. V. K. Pai, J. Environ. Biol. 30, 259 (2007).

7. R. J. Tayade, T. S. Natarajan, and H. C. Bajaj, Ind. Eng. Chem. Res. 48, 10262 (2009). http://dx.doi.org/10.1021/ie9012437

8. P. A. Carneiro, M. E. Osugi, J. J. Sene, M. A. Anderson, and M. V. B. Zanoni, Electrochim. Acta. 49, 3807 (2004). http://dx.doi.org/10.1016/j.electacta.2003.12.057

9. M. A. Aguado, M. A. Anderson, and C. G. Hill, J. Molec. Catal. 89, 165 (1994). http://dx.doi.org/10.1016/0304-5102(93)E0282-L

10. A. G. Rincón and C. Pulgarin, Appl. Catal. B: Environ. 51, 283 (2004). http://dx.doi.org/10.1016/j.apcatb.2004.03.007

11. M. Bekbolet, C. S. Uyguner, H. Selcuk, L. Rizzo, A. D. Nikolaou, S. Meric, and V. Belgiorno, Desalination 176, 155 (2005). http://dx.doi.org/10.1016/j.desal.2004.11.011

12. M. N. Chong, B. Jin, C. W. K. Chow, and C. Saint, Water Research, 44, 2997 (2010). http://dx.doi.org/10.1016/j.watres.2010.02.039

13. R. Franke and C. Franke, Chemosphere 39, 2651 (1999). http://dx.doi.org/10.1016/S0045-6535(99)00200-3

14. C. M. Ling, A. R. Mohamed, and S. Bhatia, Chemosphere 57, 547 (2004). http://dx.doi.org/10.1016/j.chemosphere.2004.07.011

15. G. McKay, J. Chem. Technol. Biotechnol. 31, 717 (1981). http://dx.doi.org/10.1002/jctb.280310197

16. R. J. Davis, J. L. Gainer, G. O. Neal, and I. Wenwu, Water Environ. Res. 66, 50 (1994). http://dx.doi.org/10.2175/WER.66.1.8

17. K. Byrappa, A. K. Subramani, S. Aananda, K. M. L. Rai, R. Dinesh, and M. Yoshimura, Bull. Mater. Sci. 29, 433 (2006). http://dx.doi.org/10.1007/BF02914073 